\title{
Synthesis, structural properties, and catalytic behavior of Cu-BTC and mixed-linker Cu-BTC-PyDC in the oxidation of benzene derivatives
}

\author{
Stefan Marx ${ }^{\mathrm{a}}$, Wolfgang Kleist ${ }^{\mathrm{a}, \mathrm{b}}$, Alfons Baiker ${ }^{\mathrm{a}, *}$ \\ anstitute for Chemical and Bioengineering, ETH Zurich, Wolfgang-Pauli-Str. 10, CH-8093 Zurich, Switzerland \\ ${ }^{\mathrm{b}}$ Institute of Catalysis Research and Technology, Karlsruhe Institute of Technology (KIT), Herrmann-von-Helmholtz-Platz 1, D-76344 Eggenstein-Leopoldshafen, Germany
}

\section{A R T I C L E I N F O}

\section{Article history:}

Received 21 January 2011

Revised 2 April 2011

Accepted 4 April 2011

Available online 11 May 2011

\section{Keywords:}

Metal-organic frameworks

Cu-BTC

Mixed-linker Cu-BTC-PyDC

Benzene derivatives

Oxidation

Hydrogen peroxide

Hydroxylation of aromatics

\begin{abstract}
A B S T R A C T
Mixed-linker metal-organic frameworks based on the Cu-BTC structure have been synthesized in which the benzene-1,3,5-tricarboxylate (BTC) linkers have been partially replaced by pyridine-3,5-dicarboxylate (PyDC). X-ray-based techniques (powder XRD and XAS), thermal analysis, and infrared spectroscopy proved that a desired amount of PyDC (up to 50\%) can be incorporated without changing significantly the crystal structure. The pyridine unit can be seen as a defect site in the local coordination environment of the dimeric copper units, which is significantly altering their electronic structure and the catalytic properties. Both Cu-BTC and the mixed Cu-BTC-PyDCs catalyze the demanding direct hydroxylation of toluene both in acetonitrile and in neat substrate. Different selectivity toward the desired ortho- and para-cresol and other oxidation products (benzaldehyde, benzyl alcohol, methylbenzoquinone) was observed for $\mathrm{Cu}-$ BTC and the Cu-BTC-PyDCs, respectively. Leaching tests and comparison with homogeneously dissolved $\mathrm{Cu}$ catalysts indicate mainly a heterogeneous reaction pathway.
\end{abstract}

(c) 2011 Elsevier Inc. All rights reserved.

\section{Introduction}

In addition to their "classic" applications in gas storage and separation, metal-organic frameworks (MOFs) have attracted the interest of researchers in the field of catalysis in recent years [1]. The crystalline, porous structure in combination with huge specific surface areas and (micro)pore volumes results in unique properties of these materials. Up to now, several different strategies have been presented in the literature to introduce catalytically active sites in metal-organic frameworks [2].

In the first approach, the MOF plays simply the role of a support material, which is used for immobilization of the active component in the form of nanoparticles or clusters inside the pores of the material [3-8]. In contrast to that, also the MOF structure itself can contain catalytically active centers at the organic linker molecules of the framework. In this case, organic molecules are utilized that feature functional side groups at the aromatic units which can act as active (e.g., basic) sites themselves $[9,10]$ or which can be further transformed by post-synthetic modification. This allows for the introduction of additional organic functional groups [11-13] as well as the immobilization of transition metal complexes via covalent bonding (or covalent tethering) [14-17]. Finally, some examples can

\footnotetext{
* Corresponding author. Fax: +41446321163.

E-mail address: baiker@chem.ethz.ch (A. Baiker).
}

be found in the literature where substrate activation in catalytic reactions takes place at coordinatively unsaturated framework metals [18-20]. Such active sites are, in general, occupied by solvent molecules which can either be replaced by the reactants or which have to be removed using activation procedures before reaction (e.g., vacuum drying).

In addition to the presence of accessible sites at the metal centers, MOF-based catalysts have to provide a sufficient stability under the applied reaction conditions. Besides thermal stability, chemical resistance (e.g., against dissolution in a certain solvent or at a given $\mathrm{pH}$ ) of the material is required. Consequently, many reports on MOF catalysis focus on the use of well-studied frameworks where these factors have been thoroughly investigated. Cu-BTC (general formula: $\mathrm{Cu}_{3}(\mathrm{BTC})_{2}\left(\mathrm{H}_{2} \mathrm{O}\right)_{3}$, also known as HKUST-1 [21] or MOF-199 [22], represents one of the most famous examples of a metal-organic framework possessing all the required conditions. While the synthesis of phasepure Cu-BTC was difficult in the beginning (metallic and oxidic $\mathrm{Cu}$ species were found as the main side products in early solvothermal procedures) [21], several optimized routes have been published recently [23] that opened possibilities for large-scale production of Cu-BTC, which is an important pre-requisite for catalytic applications. These include electrochemical methods [1] and high-throughput screening [24] as well as ultrasonic [25] and microwave [26] assisted procedures. In addition, the growth of Cu-BTC nanocrystals on support materials has been presented [27-29]. 
The SBU (secondary building unit) of Cu-BTC consists of a dimeric copper unit that is bridged by four carboxylate functionalities of four BTC molecules. The resulting paddle-wheel moiety is a characteristic motif for copper carboxylates. Each copper atom is octahedrally coordinated by four oxygen and one copper atom. The remaining, free coordination site, which is in the as-prepared form occupied by a solvent molecule like water, represents the possible active site for catalytic transformations. In Fig. 1 (top), the crystal structure of Cu-BTC is depicted. The secondary building unit (SBU) and the processes occurring during dehydration and substrate coordination are schematically shown in Fig. 1 (bottom).

The accessibility of these sites has been proven both experimentally [30] and based on simulations [31-33]. Consequently, $\mathrm{Cu}-\mathrm{BTC}$ has been used in some catalytic applications up to now. Kaskel et al. reported on the cyanosilylation of carbonyl compounds, namely benzaldehyde and acetone, at low temperatures $\left(40-80^{\circ} \mathrm{C}\right)$ in the liquid phase [34]. The catalytic activity of the Lewis-acidic $\mathrm{Cu}$ centers in the water-free form $\mathrm{Cu}_{3}(\mathrm{BTC})_{2}$ has been tested in the isomerization of $\alpha$-pinene oxide and the cyclization of citronellal by De Vos and coworkers [18]. Also other Cu-based metal-organic frameworks have been reported as catalysts in oxidation reactions of, e.g., xanthene [20] and hydrochinone [35] or the epoxidation of olefins [36]. While the synthesis of phenol itself is straightforward via the cumene process, the hydroxylation of substituted benzene derivatives is possible by multi-level procedures, e.g., by the synthesis of the corresponding diazonium compound and its hydrolysis. Therefore, a direct hydroxylation of benzene or related aromatic compounds under mild conditions and with a green oxidation reagent would be desirable. In one of the rare examples of direct hydroxylation of phenol (to produce hydrochinone, catechol, and traces of benzoquinone), a copper complex immobilized in molecular sieves was utilized [37]. Since this transformation is a quite demanding reaction, only very small turnover frequencies in the range of $0.15-1.04 \mathrm{~h}^{-1}$ have been reported in that work. For an overview on the activities in the field of oxidation of aromatics, the reader is referred to the review by Lücke et al. [38].

The main objective of the present work was to answer the question whether the local coordination sphere of the copper centers in the structure, and thus the electronic and catalytic properties of $\mathrm{Cu}-\mathrm{BTC}$, could be modified by introducing a desired amount of modified linker molecules in the structure. In previous works, it has been demonstrated that this mixed-linker metal-organic framework (MIXMOF) concept can be used to introduce catalytically active groups as side groups of the organic-linkers, which are well distributed over the whole framework $[8,10]$. In contrast to that, our target was to substitute a certain amount of benzene-1,3,5-tricarboxylate (BTC) linker molecules by pyridine-3,5dicarboxylate (PyDC) in order to check whether these molecules can be incorporated in the $\mathrm{Cu}$-BTC structure without changing its crystal structure. The pyridine group could then be seen as a defect site in the crystal lattice, which leads to a paddle-wheel unit where one of the bridging carboxylate groups is missing and replaced by the nitrogen of the pyridine ring (Scheme 1). This should affect electronic (e.g., the bond strength and distance of the coordinated water molecules or the $\mathrm{Cu}-\mathrm{Cu}$ distance) and consequently also the catalytic properties of the $\mathrm{Cu}$ centers in the framework. We applied $\mathrm{X}$-ray-based techniques (X-ray diffraction and X-ray absorption spectroscopy) as well as thermal analysis, infrared spectroscopy and electron microscopy for structural investigations and used the direct hydroxylation of benzene and its derivatives (both using acetonitrile as the solvent and in neat substrate) as the target reaction to demonstrate the catalytic properties of the resulting $\mathrm{Cu}$ BTC-PyDC MIXMOFs.

\section{Experimental}

\subsection{Material synthesis}

About $1.126 \mathrm{~g}(4.84 \mathrm{mmol})$ of $\mathrm{Cu}\left(\mathrm{NO}_{3}\right)_{2} * 2.5 \mathrm{H}_{2} \mathrm{O}$ was dissolved in $25 \mathrm{ml}$ of distilled water, and $0.491 \mathrm{~g}$ of benzene-1,3,5-tricarboxylic acid $\left(\mathrm{H}_{3} \mathrm{BTC} ; 2.33 \mathrm{mmol}\right)$ was dissolved in $25 \mathrm{ml}$ of $\mathrm{N}, \mathrm{N}$ dimethylformamide (DMF). The two solutions were combined in a $100-\mathrm{ml}$ round-bottom flask that was put in a pre-heated oil bath at a temperature of $100{ }^{\circ} \mathrm{C}$ for $4 \mathrm{~h}$. The blue precipitate was then filtered off, washed thoroughly with DMF and water to remove residual precursor species, and dried at $200^{\circ} \mathrm{C}$ in order to remove the DMF solvent. The Cu-BTC-PyDC catalysts have been synthesized accordingly, with the only difference that $10,20,30,40,50$, and 90 mol\% of $\mathrm{H}_{3} \mathrm{BTC}$, respectively, have been replaced by $\mathrm{H}_{2}$ PyDC. While pure $\mathrm{Cu}-\mathrm{BTC}$ is turquoise in its as-synthesized form, it turned to dark blue after drying at $200^{\circ} \mathrm{C}$. The substituted $\mathrm{Cu}-$ BTC-PyDC samples have the same color like the original one with the only difference that with increasing degree of substitution the color becomes a bit less intense.
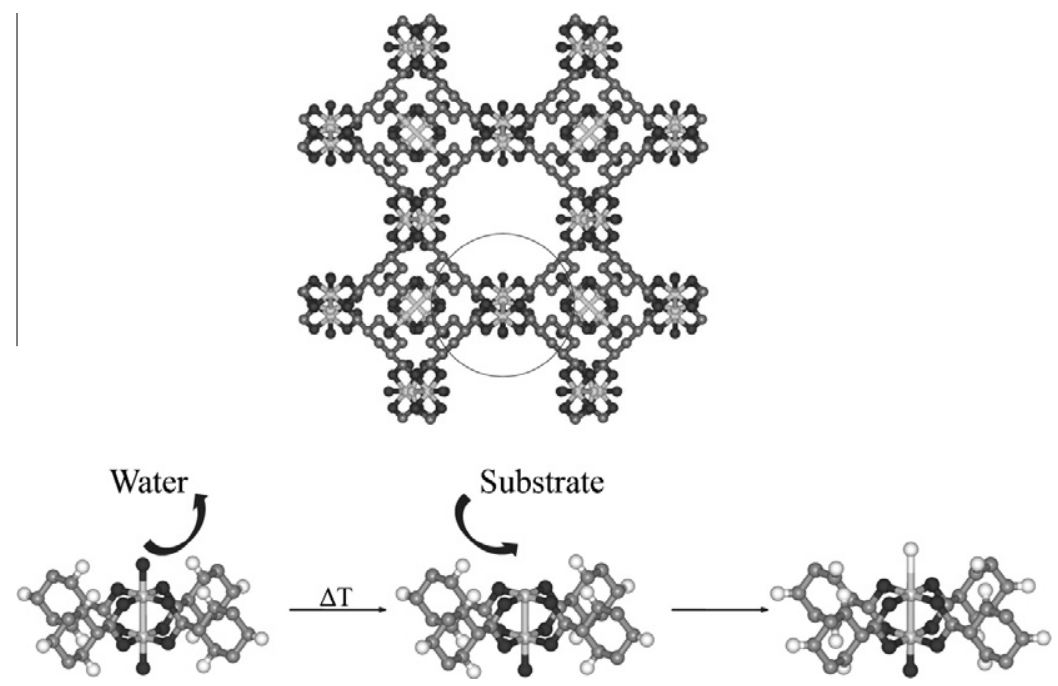

Fig. 1. Elementary cell of Cu-BTC (top) and structural changes at the $\mathrm{Cu}$ centers occurring during dehydration and substrate coordination. 

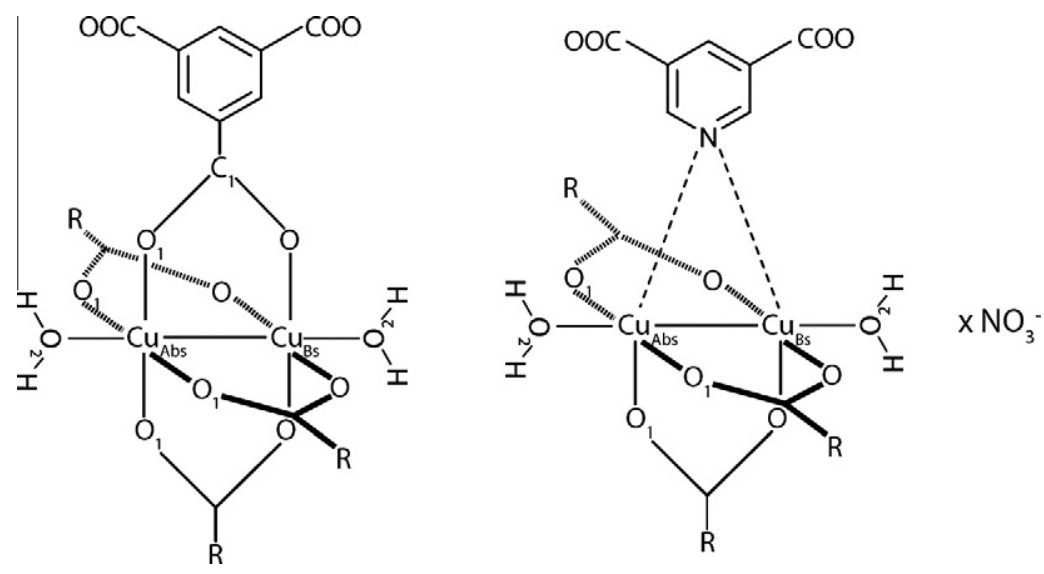

Scheme 1. Illustration of replacing BTC by PyDC.

\subsection{Atomic absorption spectroscopy AAS}

Leaching of $\mathrm{Cu}$ was determined by AAS (atomic absorption spectroscopy). The measurement was performed with a Varian SpectrAA 220 FS spectrometer. The reaction mixture was filtered, the organic and aqueous phases were separated, and the copper content was determined by a calibration curve recorded before.

\subsection{IR investigations}

IR-investigations were performed using a Vertex 77 FT-IR spectrometer (Bruker Optics) in ATR mode. The powder was milled and stored at atmospheric conditions for $30 \mathrm{~min}$ to warrant similar conditions and comparability of the spectra. The spectrometer was equipped with a liquid nitrogen cooled MCT detector and a Platinum ATR unit. The resolution was set to $4 \mathrm{~cm}^{-1}$, and the spectra were recorded in the range between 7500 and $500 \mathrm{~cm}^{-1}$. About 200 scans were averaged to one spectrum.

\subsection{Electron microscopy}

Cu-BTC and Cu-BTC0.5PyDC0.5 have been placed on a carbon foil. The samples were measured under high vacuum on a 1530 Gemini (Zeiss; field emission gun) operated at $1 \mathrm{kV}$.

\subsection{X-ray absorption measurements}

The experiments were performed at the Hamburger Synchrotronstrahlungs-Labor (HASYLAB) at Deutsches Elektronen-Synchrotron (DESY) at DORIS III (4.45 GeV, $120 \mathrm{~mA}$ current) using beam line X1 (energy range: $7-100 \mathrm{keV}$ ). The monochromator was a $\mathrm{Si}\left(\begin{array}{lll}1 & 1 & 1\end{array}\right)$ crystal for the measurement at the $\mathrm{Cu}$ K-edge $(8.979 \mathrm{keV})$. To prevent higher harmonics, the crystal was detuned to $65 \%$. All samples were measured in transmission mode. To monitor the dehydration of the $\mathrm{Cu}-\mathrm{BTC}$, an in situ flow cell was filled with the as-prepared catalyst (admixed with $\mathrm{Al}_{2} \mathrm{O}_{3}$ in order to obtain the optimum $\mathrm{Cu}$ concentration for the XAS measurements). He was passed through the cell which was heated to $162{ }^{\circ} \mathrm{C}$ while XANES spectra were taken. The final temperature was kept until no changes in two subsequent XANES spectra were discernible. After cooling to room temperature, EXAFS spectra of the samples were taken.

The raw data were energy calibrated toward copper foil, background corrected using a two polynomial fit, and normalized. The $\chi(k)$ function was extracted from the EXAFS data in the range between 0.5 and $16.0 \AA^{-1}$ and Fourier transformation was performed on the $k^{3}$ weighted data in the interval $k=2.6-14.9 \AA^{-1}$.
Data analysis was performed using scattering paths calculated with FEFF 7.0 [39]. The feff input file was generated using crystal structures of Cu-BTC. The calculated amplitudes and phase shifts have been fitted to the experimentally obtained data. In a first step, the reference spectra of Cu-BTC were fitted taking four next neighbors into consideration.

\subsection{Thermogravimetry}

Thermoanalytical (TA) experiments were carried out isothermally or non-isothermally (heating rates were generally in the range of $5-10 \mathrm{~K} \mathrm{~min}^{-1}$ ) on a Netzsch STA 409 simultaneous thermal analyzer. The determination of the thermal stability of the MOFs was made in He atmosphere, using a total gas flow of $50 \mathrm{~mL} \mathrm{~min}^{-1}$.

\subsection{Catalytic tests in acetonitrile}

The catalytic test reactions were performed using an eightfold parallel batch reactor system (Endeavor Catalysts Screening System). Each reactor was equipped with a glass inlet and a stirrer. The temperature and the pressure could be programmed for each reactor separately. The reaction mixture was purged with nitrogen, and a pressure of 2 bar of nitrogen was added to the system. About $440 \mathrm{mg}$ (4.78 mmol) of toluene (VWR, 99.9\%), $12.4 \mathrm{mg}$ $(0.097 \mathrm{mmol})$ of nonane (Fluka $99.0 \%)$ as internal standard, and $4.5 \mathrm{ml}$ acetonitrile (Sigma-Aldrich, 99.5\%) were mixed in a glass inlet. Twenty milligram $(0.033 \mathrm{mmol})$ of the catalyst was added to the solution as well as $1.06 \mathrm{~g}$ of an aqueous solution of $\mathrm{H}_{2} \mathrm{O}_{2}$ (Merck, 30\%), which corresponds to 2 eq. of peroxide based on toluene.

\subsection{Catalytic tests under solvent-free conditions}

The catalytic test reactions were performed in the same parallel batch reactor system. In a typical experiment, $20 \mathrm{mg}(0.033 \mathrm{mmol})$ of the catalyst, $46.9 \mathrm{mmol}$ of the substrate, and nonane (Fluka 99.0\%) as internal standard were placed in the glass inlet. The ratio of the amount of copper atoms to the amount of substrate was kept at around $0.21 \mathrm{~mol} \%$. The experiment was started with the addition of $30 \% \mathrm{H}_{2} \mathrm{O}_{2}$ aqueous solution to the mixture. The amount of the $\mathrm{H}_{2} \mathrm{O}_{2}$ solution was adjusted that the molar ratio of $\mathrm{H}_{2} \mathrm{O}_{2}$ to substrate was $0.1,0.2,0.4$, or 0.8 (corresponding to $0.476,0.938$, 1.877 , and $3.754 \mathrm{ml}$ of hydrogen peroxide solution). The reaction mixture was purged with nitrogen, and a pressure of 2 bar of nitrogen was added to the system. Stirring at $250 \mathrm{rpm}$ guaranteed an intimate mixing of the phases. The reaction mixture was analyzed 
after separation of the phases and drying of the organic phase over $\mathrm{MgSO}_{4}$ with a HP $6890 \mathrm{GC}$ system on a HP-5 column $(30 \mathrm{~m})$ equipped with a FID. A temperature program has been applied starting at $40{ }^{\circ} \mathrm{C}$ increasing to $250^{\circ} \mathrm{C}$ after $5 \mathrm{~min}$.

\section{Results and discussion}

\subsection{Structural investigations of $C u-B T C$ and the $C u-B T C-P y D C$ catalysts}

\subsection{1. $\mathrm{Cu}-\mathrm{BTC}$}

The $\mathrm{Cu}-\mathrm{BTC}$ catalyst used in this work was synthesized using a modified experimental procedure at low temperature $\left(100^{\circ} \mathrm{C}\right)$ using water/ $\mathrm{N}, \mathrm{N}$-dimethylformamide (DMF) mixtures as the solvent instead of water/ethanol. In contrast to the common solvothermal routes, this low-temperature synthesis could be done via precipitation in a round-bottom flask, because of the good solubility of the organic precursor in DMF (in contrast to ethanol). This method has been chosen to allow for a controlled precipitation of the catalyst in order to avoid the formation of undesired phases. Furthermore, the applied soft precipitation method should be beneficial for the synthesis of the mixed BTC-PyDC catalysts. The assynthesized material was subsequently dried at $200^{\circ} \mathrm{C}$ in order to remove the DMF solvent, which might be bound more strongly than water. The measured BET surface area of the dried material $\left(1700 \mathrm{~m}^{2} / \mathrm{g}\right)$ was comparable to the values reported in the literature. To prove that solvent molecules could be removed from the $\mathrm{Cu}$ centers by thermal treatment, in situ X-ray absorption studies were performed to investigate the local environment of the Cu centers in the structure. To give further evidence to this claim, the subsequent dehydration process of the material was monitored by in situ XANES spectroscopy.

In Fig. 2 three exemplary XANES spectra at $33^{\circ} \mathrm{C}, 109^{\circ} \mathrm{C}$, and $162^{\circ} \mathrm{C}$ are depicted. The white line for the hydrated sample is found at $8.9975 \mathrm{keV}$ and shifts to $8.9982 \mathrm{keV}$ for the dehydrated one. Additionally, the intensity of the white line decreases upon heating. The blue shift and the decrease in the white line intensity indicate the decrease in the coordination number of the copper atoms due to the loss of coordinated water. A second indication for the removal of water is given by the increase and red shift of the pre-edge feature at around $8.985 \mathrm{keV}$ (inset in Fig. 3). This feature corresponds to a $1 \mathrm{~s}$ to $4 \mathrm{p}$ transition combined with a charge transfer from the ligand to the metal. Both effects together give a so-called shakedown transition $\left[1 \mathrm{~s}(2) \ldots 3 \mathrm{~d}(9) 4 \mathrm{p}(0) \mathrm{L}^{0}\right]$ to $\left[1 \mathrm{~s}(1) \ldots 3 \mathrm{~d}(10) 4 \mathrm{p}(1) \mathrm{L}^{1+}\right]$. Upon the loss of a coordinated water molecule, the copper atom becomes more electrophilic, resulting

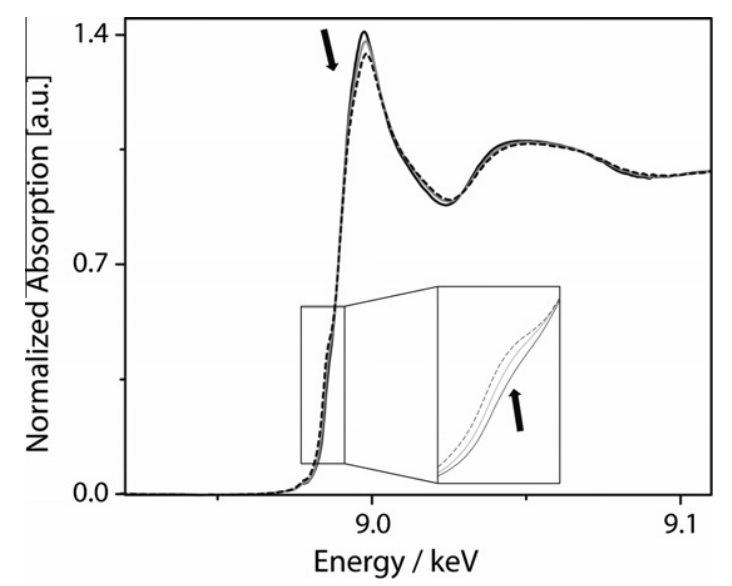

Fig. 2. In situ XANES spectra of the dehydration process of $\mathrm{Cu}-\mathrm{BTC}$. The inset magnifies the pre-edge feature attributed to a $1 \mathrm{~s} \rightarrow 4 \mathrm{p}$ dipole shakedown transition.

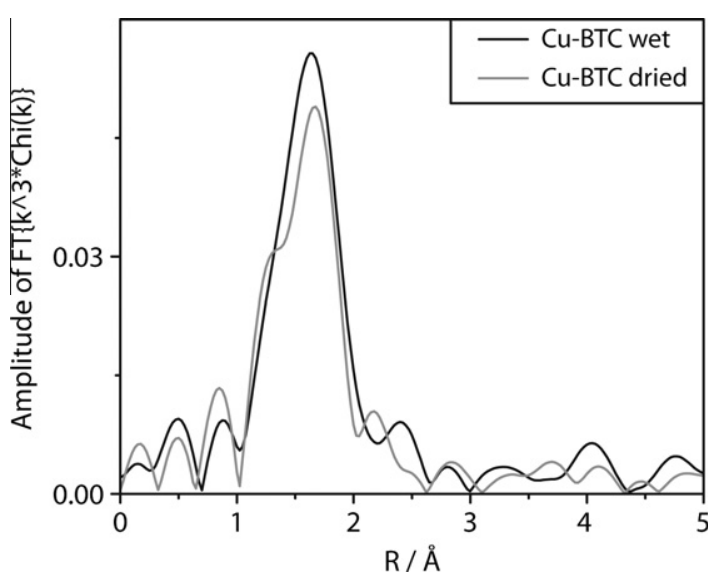

Fig. 3. Fourier-transformed EXAFS spectra ( $k^{3}$ weighted) of the as-prepared and the dehydrated $\mathrm{Cu}-\mathrm{BTC}$.

in a strengthening of the $\mathrm{Cu}-\mathrm{O}_{\text {carboxylate }}$ bond. The stronger binding of the ligand to the copper facilitates the shakedown transition, resulting in the observed increase and red shift of this pre-edge feature from $8.9848 \mathrm{keV}$ to $8.9841 \mathrm{keV}$ [40].

After the completion of the drying process, an EXAFS measurement of the dried sample was performed (Fig. 3), which revealed that the Fourier-transformed spectra of the as-prepared and the dried sample differ slightly. For the activated material, a backscatter contribution occurs as a shoulder at low $R$ values, indicating a shortening of the $\mathrm{Cu}-\mathrm{O}_{\text {carboxylat }}$ bonds after water removal. Additionally, the amplitude of the dried sample is less intense than the one of the as-prepared sample hinting at the presence of less next neighbors around the copper center.

Both methods indicate the removal of water and the generation of a free coordination site (Fig. 1) in the material synthesized in this work. This means that the copper atoms do not only serve as SBU (secondary building unit) but could act as active centers in a catalytic reaction.

\subsection{2. $C u-B T C-P y D C$}

The influence of the substitution of benzene-1,3,5-tricarboxylate (BTC) by pyridine-3,5-dicarboxylate (PyDC) on the structure has been studied by XRD and XAS techniques (see Scheme 1). By exchanging one BTC molecule by PyDC, one carboxylate group (out of three) of one linker molecule is replaced by one nitrogen atom in the aromatic ring. Thus, the paddle-wheel structure should become distorted, and a gap should occur between the copper dimer and the linker molecule. Up to $50 \%$ of the BTC linkers could be introduced into the framework without changing the structure of the original Cu-BTC as indicated by XRD (Fig. 4). Since higher ratios of PyDC (e.g., 90\%) resulted in the formation of a completely different crystal structure, we used only the materials containing $10 \%, 20 \%, 30 \%$, and $50 \%$ of PyDC for the further studies.

To gain a deeper understanding of the geometric and electronic changes in the modified framework, EXAFS and XANES investigations have been performed. Comparison of $\mathrm{Cu}-\mathrm{BTC}$ and $\mathrm{Cu}-$ $\mathrm{BTC}_{0.5} \mathrm{PyDC}_{0.5}$ XANES spectra reveals several differences (Fig. 5). The white line intensity of the substituted MOF is smaller compared to the pure MOF indicating less next neighbors, similar to observation made for dehydration of the MOF. In difference to dehydration, substitution leads to a red shift of the white line by about $0.0009 \mathrm{keV}$. Additionally, the pre-edge feature found for Cu-BTC at $8.985 \mathrm{keV}$ (see inset in Fig. 5) is not visible for the substituted MOF. Thus, the change in the coordination surrounding leads to an increase in the electron density at the copper atoms [30]. 


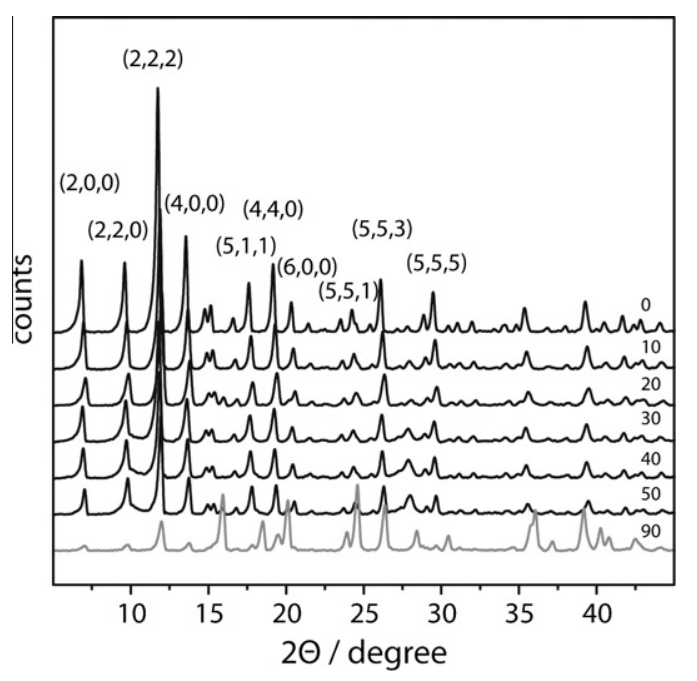

Fig. 4. Powder X-ray diffraction pattern of pure Cu-BTC and the Cu-BTC-PyDC materials; the percentage of BTC linkers that were replaced by PyDC is marked on the curves.

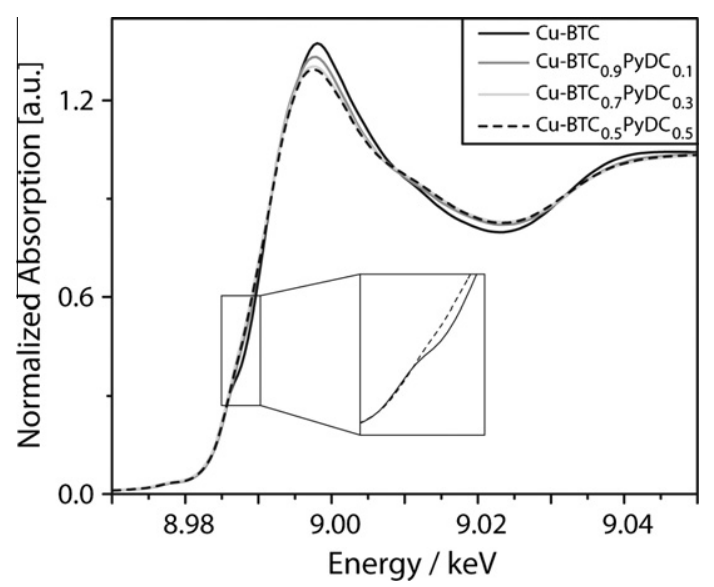

Fig. 5. Comparison of the XANES region of $\mathrm{Cu}-\mathrm{BTC}$ (black line, -) and selected $\mathrm{Cu}$ BTC-PyDC materials. The inset magnifies the pre-edge feature attributed to a $1 \mathrm{~s} \rightarrow 4 \mathrm{p}$ dipole shakedown transition.

In Fig. 6, the Fourier-transformed EXAFS spectra of pure Cu-BTC and the modified Cu-BTC-PyDC materials are depicted. With increasing PyDC content, the amplitude becomes smaller, indicating a decrease in the coordination number of the copper atoms. At larger distances, the scattering pattern shows also slight differences especially for the transition from the unmodified MOF to the substituted ones. To quantify the changes visible in the EXAFS pattern, the spectra have been fitted (Table 1 ).

Two assumptions have been made for the fitting procedure. First, for a Cu-BTC-PyDC material, the coordination numbers $\mathrm{N}_{\mathrm{Cu}-\mathrm{O} 1}$ and $\mathrm{N}_{\mathrm{Cu}-\mathrm{C} 1}$ should be identical, since the removal of a carboxylate ligand reduces the number of $\mathrm{O}_{1}$ and $\mathrm{C}_{1}$ atoms in the same manner. Second, the coordination number $\mathrm{N}_{\mathrm{Cu}-\mathrm{Cu}}$ should be one in all cases. The results of fitting for the pure $\mathrm{Cu}-\mathrm{BTC}$ and the mixed Cu-BTC-PyDC MOFs with 10\%, 30\%, and 50\% of PyDC reveal several changes in the local structure around the $\mathrm{Cu}$ atoms. As expected, the coordination numbers $\mathrm{N}_{\mathrm{Cu}-\mathrm{O} 1 \text { and }} \mathrm{N}_{\mathrm{Cu}-\mathrm{C} 1}$ were decreasing upon increasing the amount of PyDC. While a coordination number of 4.0 (which is expected for the unmodified $\mathrm{Cu}-\mathrm{BTC}$ ) is found for the samples containing $0 \%$ and $10 \%$ of PyDC, respectively, this value changes to 3.6 and 3.4 for the samples with $30 \%$ and $50 \%$ of PyDC. The decrease in $\mathrm{N}_{\mathrm{Cu}-\mathrm{O} 1}$ and $\mathrm{N}_{\mathrm{Cu}-\mathrm{C} 1}$ should be around 0.66 for the

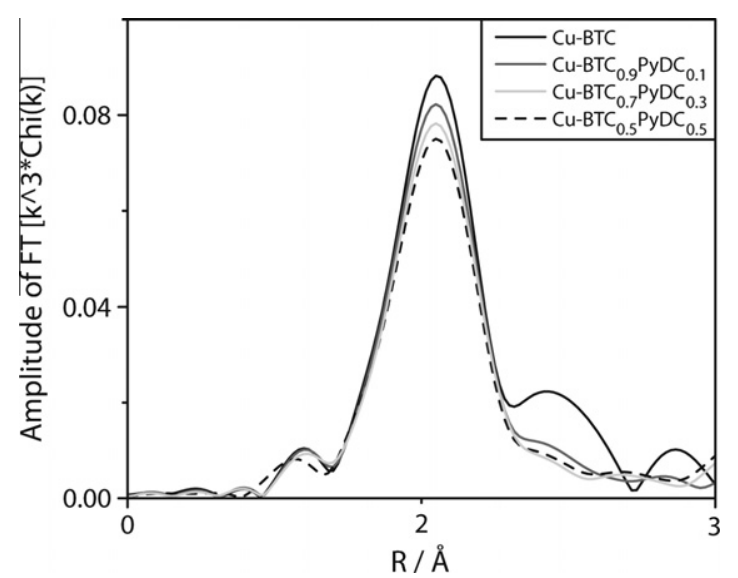

Fig. 6. Fourier-transformed EXAFS spectra ( $k^{3}$ weighted) of $\mathrm{Cu}-\mathrm{BTC}$ and substituted $\mathrm{Cu}-\mathrm{BTC}_{x} \mathrm{PyDC}_{1-x}$ samples.

sample with 50\% PyDC, since half of the BTC ligands are replaced by PyDC, meaning that $1 / 6$ of all carboxylate ligands are missing. Therefore, the average coordination numbers $\mathrm{N}_{\mathrm{Cu}-\mathrm{O} 1}$ and $\mathrm{N}_{\mathrm{Cu}-\mathrm{C} 1}$ should be 3.3, which is close to the value of 3.4 that is found by simulation (Table 1). The amount of water bonded to the $\mathrm{Cu}$ atoms stays constant for up to $30 \%$ PyDC, and a slightly higher coordination number of 1.2 was found for the last sample. We assume that these additional water molecules might coordinate at the distorted $\mathrm{Cu}$ centers, which would otherwise have only a coordination number of five. Consequently, the framework structure should be less rigid compared to the pure $\mathrm{Cu}-\mathrm{BTC}$, which should also alter the possibilities of substrate coordination during catalytic processes. As mentioned above, a higher degree of substitution (e.g., 90\% of PyDC) leads to restructuring and the formation of a different crystal phase, whereas the Cu-BTC structure stays intact when up to $50 \%$ of the linker is substituted by PyDC. In addition, the distance between the two $\mathrm{Cu}$ atoms in the dimer becomes smaller by $0.3 \AA$, while the distance between $\mathrm{Cu}$ and $\mathrm{C}_{1}$ increases by $0.6 \AA$ with increasing PyDC content. Thus, a strain on the SBU as well as electronic effects upon substitution could be proven by XAS analysis.

Nevertheless, the question for the balance of the remaining positive charge is rather demanding. Upon substitution of BTC by PyDC, one carboxylate group is missing and a positive charge remains in that structure. Thus, residual nitrate ions or hydroxide species might compensate the additional charge. On the other hand, a certain amount of $\mathrm{Cu}^{2+}$ ions could in principle be reduced to $\mathrm{Cu}^{+}$to balance the charge. The change of the valence state seems unlikely, since the XANES investigations rule out the existence of $\mathrm{Cu}^{+}$ions in the material. In the case of $\mathrm{Cu}-\mathrm{BTC}_{0.5} \mathrm{PyDC}_{0.5}, 1 / 6$ of all $\mathrm{Cu}$ ions should then be $\mathrm{Cu}^{+}$, which should be visible in the XANES spectra (I) as a shift of the edge energy by $0.0035 \mathrm{keV}$ to lower values, (II) by an increase in the pre-edge feature at $8.984 \mathrm{keV}$, and (III) by a significant decrease in the white line intensity [41]. Therefore, the presence of nitrate or hydroxide ions as source of the additionally needed negative charges is likely although it was not unambiguously possible to prove their incorporation with EXAFS and to determine their exact location.

Thermogravimetric results are shown in Fig. 7 and Fig. S1 in Supporting information (SI), which clearly indicate that pure $\mathrm{Cu}$ BTC is the most stable compound and that the thermal stability of the substituted materials decreased with increasing PyDC content (Fig. 7a). Thus, the onset of decomposition of Cu-BTC was around $300{ }^{\circ} \mathrm{C}$, while $\mathrm{Cu}-\mathrm{BTC}_{0.5} \mathrm{PyDC}_{0.5}$ started to decompose already at $270{ }^{\circ} \mathrm{C}$ (Fig. $7 \mathrm{~b}$ ). Water could be removed between $50{ }^{\circ} \mathrm{C}$ and $150{ }^{\circ} \mathrm{C}$ being in good agreement with the XANES investigation, where the water was removed after reaching a temperature of $160{ }^{\circ} \mathrm{C}$. 
Table 1

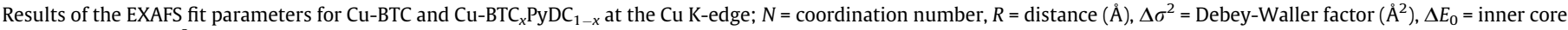
correction $\left(\mathrm{keV} * 10^{3}\right)$.

\begin{tabular}{|c|c|c|c|c|c|c|c|}
\hline Sample & Edge & Pair & $N$ & $R$ & $\Delta \sigma^{2}$ & $\Delta E_{0}$ & Residual \\
\hline $\mathrm{Cu}-\mathrm{BTC}$ & $\mathrm{Cu} \mathrm{K}$ & $\begin{array}{l}\mathrm{Cu}-\mathrm{O}_{1} \\
\mathrm{Cu}-\mathrm{O}_{2} \\
\mathrm{Cu}-\mathrm{Cu} \\
\mathrm{Cu}-\mathrm{C}_{1}\end{array}$ & $\begin{array}{l}4.0 \\
1.0 \\
1.0 \\
4.0\end{array}$ & $\begin{array}{l}1.96 \\
2.01 \\
2.61 \\
2.80\end{array}$ & $\begin{array}{l}0.0043 \\
0.0050 \\
0.0068 \\
0.0073\end{array}$ & $\begin{array}{r}9.0 \\
-4.8 \\
9.9 \\
8.8\end{array}$ & 4.9 \\
\hline 10\% PyDC & $\mathrm{Cu} \mathrm{K}$ & $\begin{array}{l}\mathrm{Cu}-\mathrm{O}_{1} \\
\mathrm{Cu}-\mathrm{O}_{2} \\
\mathrm{Cu}-\mathrm{Cu} \\
\mathrm{Cu}-\mathrm{C}_{1}\end{array}$ & $\begin{array}{l}4.0 \\
1.0 \\
1.0 \\
4.0\end{array}$ & $\begin{array}{l}1.96 \\
2.08 \\
2.60 \\
2.80\end{array}$ & $\begin{array}{l}0.0044 \\
0.0080 \\
0.0080 \\
0.0050\end{array}$ & $\begin{array}{r}9.4 \\
9.6 \\
-0.2 \\
-2.9\end{array}$ & 3.4 \\
\hline $30 \%$ PyDC & $\mathrm{Cu} \mathrm{K}$ & $\begin{array}{l}\mathrm{Cu}-\mathrm{O}_{1} \\
\mathrm{Cu}-\mathrm{O}_{2} \\
\mathrm{Cu}-\mathrm{Cu} \\
\mathrm{Cu}-\mathrm{C}_{1}\end{array}$ & $\begin{array}{l}3.6 \\
1.0 \\
1.0 \\
3.6\end{array}$ & $\begin{array}{l}1.95 \\
2.04 \\
2.59 \\
2.84\end{array}$ & $\begin{array}{l}0.0048 \\
0.0083 \\
0.0108 \\
0.0063\end{array}$ & $\begin{array}{r}8.4 \\
9.7 \\
-9.9 \\
-4.0\end{array}$ & 2.8 \\
\hline $50 \%$ PyDC & $\mathrm{Cu} \mathrm{K}$ & $\begin{array}{l}\mathrm{Cu}-\mathrm{O}_{1} \\
\mathrm{Cu}-\mathrm{O}_{2} \\
\mathrm{Cu}-\mathrm{Cu} \\
\mathrm{Cu}-\mathrm{C}_{1}\end{array}$ & $\begin{array}{l}3.4 \\
1.2 \\
1.0 \\
3.4\end{array}$ & $\begin{array}{l}1.95 \\
2.00 \\
2.58 \\
2.86\end{array}$ & $\begin{array}{l}0.0054 \\
0.0070 \\
0.0111 \\
0.0076\end{array}$ & $\begin{array}{r}8.3 \\
8.3 \\
-8.1 \\
1.2\end{array}$ & 3.7 \\
\hline
\end{tabular}
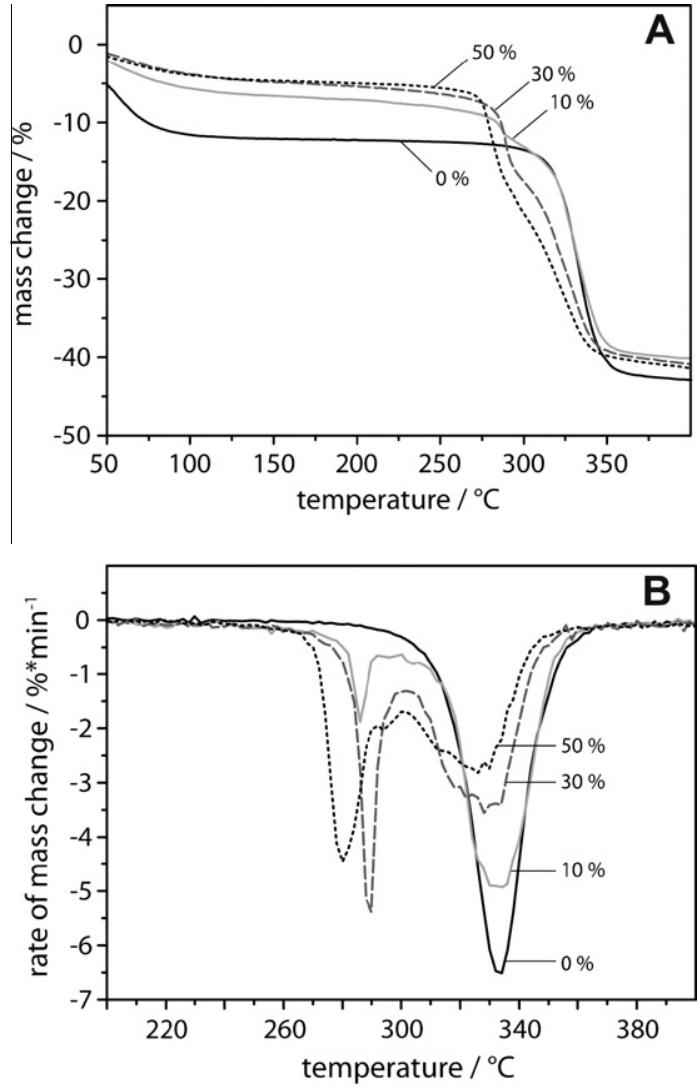

Fig. 7. (A) Thermogravimetric measurements of MOFs with $0,10,30$, and $50 \mathrm{~mol} \%$ PyDC; (B) differential thermogravimetric measurements of MOFs with $0,10,30$, and $50 \mathrm{~mol} \%$ PyDC.

Evaluation of the DTG data (Fig. 7b) revealed that the thermal decomposition of the mixed Cu-BTC-PyDCs occurred in two steps. While only one maximum of the decomposition rate (at ca. $330^{\circ} \mathrm{C}$ ) was found for the pure Cu-BTC, a second feature at $280-290^{\circ} \mathrm{C}$ appeared for the mixed-linker MOFs. Assuming that the missing carboxylate group of the PyDC results in a weaker interaction of the pyridine function with the $\mathrm{Cu}$ centers (compared to the BTC linker), it is reasonable that the structure starts to break at these defect sites already at lower temperatures. The increasing intensity of this low temperature signal (combined with the decreasing intensity of the signal assigned to the BTC linkers) is in perfect accordance with the higher degree of substitution, proving the incorporation of both types of linker into the structure.

IR spectra of the series of MOFs are depicted in Fig. 8 and Fig. S2. In the range between $1700 \mathrm{~cm}^{-1}$ and $1500 \mathrm{~cm}^{-1}$, the signals for the antisymmetric stretch vibrations of the carboxylate group $\left[v_{\text {as }}(\mathrm{O}-\right.$ $\mathrm{CO})]$ of BTC and PyDC are discernible. For the BTC ligand, $v_{\text {as }}(\mathrm{OCO})$ is located at around $1640 \mathrm{~cm}^{-1}$ [42]. All six samples exhibited the signal for BTC as shown in Fig. 8a, and only a small red shift of 20 wave numbers was observed upon substitution with PyDC. The signal for $v_{\text {as }}(\mathrm{OCO})$ of PyDC is normally found at lower wave number [43]. Thus, the signal at $1560 \mathrm{~cm}^{-1}$ was assigned to the carboxylate group of PyDC. This signal is increasing with increasing PyDC content. A second characteristic signal is shown in Fig. 8b. The $\mathrm{C}-\mathrm{H}$ in plane bending mode of the aromatic ring in Cu-BTC is observed at $1105 \mathrm{~cm}^{-1}$, which is in good agreement with literature values [42]. With increasing PyDC content, a signal at $1096 \mathrm{~cm}^{-1}$ appeared, indicating the presence of a second linker with a different substitution pattern of the aromatic ring.

In summary, IR studies, TG analysis as well as EXAFS investigations corroborated the incorporation of both linker molecules into the framework structure. Powder XRD indicated that the crystal structure was sustained up to a substitution degree of $50 \%$. We also investigated whether the exchange of BTC by PyDC had an influence on the morphology of the crystals using scanning electron microscopy. SEM images of $\mathrm{Cu}-\mathrm{BTC}$ and $\mathrm{Cu}-\mathrm{BTC}_{0.5} \mathrm{PyDC}_{0.5} \mathrm{com}-$ pared in Fig. 9 and Fig. S3 do not indicate a significant change in the morphology up to the maximum possible substitution degree.

\subsection{Catalytic tests of Cu-BTC and the modified Cu-BTC-PyDC materials}

We have chosen the demanding direct hydroxylation of benzene derivatives, e.g., toluene, in the presence of hydrogen peroxide (Scheme 2) as the target reaction to check the potential of the modified Cu-BTC materials in catalysis and the influence of the structural "defects" that have been introduced by the substitution of BTC by PyDC. The chosen test reaction is of importance since phenol and its derivatives are versatile building blocks for the synthesis of pharmaceuticals, polymers, and natural products [44].

\subsubsection{Oxidation of toluene in acetonitrile}

First, the oxidation of toluene using $\mathrm{H}_{2} \mathrm{O}_{2}$ as the oxidant (Scheme 2) was studied in acetonitrile, which was chosen as the 

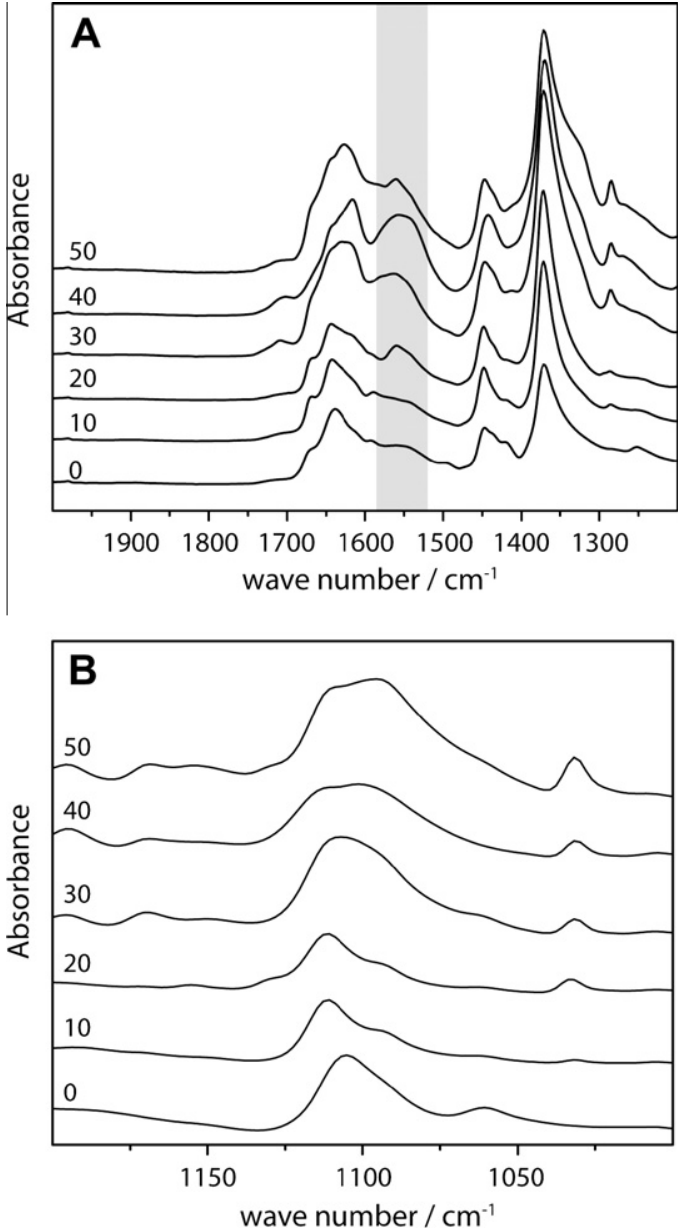

Fig. 8. A) IR spectra of MOFs with a molar PyDC content between $0 \%$ and $50 \%$; frequency range for $v_{\mathrm{as}}(\mathrm{OCO})$ of the BTC and PyDC ligand in the metal-organic framework (gray area indicates the signal for $v_{\text {as }}(\mathrm{OCO})$ of PyDC); B) frequency range of the $\mathrm{C}-\mathrm{H}$ in plane bending mode of BTC and PyDC.

solvent because of the solubility of both reactants (toluene and hydrogen peroxide) in this medium.

In Table 2, the conversion of toluene is listed under different reaction conditions. As expected, higher temperatures and longer reaction times are beneficial for the conversion. Almost no conversion was observed at $40{ }^{\circ} \mathrm{C}(0.14 \%$, Table 2 , entry 1$)$ and $50{ }^{\circ} \mathrm{C}$ $(0.21 \%$, Table 2 , entry 5$)$ after one hour of reaction. Increasing the temperature to $80{ }^{\circ} \mathrm{C}$ resulted, however, in a slightly higher conversion of ca. $1.27 \%$ (Table 2, entry 13). Furthermore, conversion could also be more than doubled by doubling the reaction time (e.g., from $0.62 \%$ to $1.51 \%$ at $70^{\circ} \mathrm{C}$, Table 2 , entries 11 and 12 ). Much longer reaction times $(18 \mathrm{~h})$ turned, however, out to be not very efficient, which can simply be explained by the fact that the $\mathrm{H}_{2} \mathrm{O}_{2}$ oxidant is decomposed thermally after a certain time. Finally, we discovered that a further dilution of the substrate concentration (from 10 to 5 vol.\%) had a beneficial influence on the conversion, which could be increased from $1.27 \%$ to almost $5 \%$ after one hour at $80^{\circ} \mathrm{C}$ (Table 2, entries 13 and 14). Note that this latter value corresponds to a TOF of 2.37, which is more than twice the value that has been reported in the work of Raja and Ratnasamy [37].

The catalytic results obtained from the reaction with Cu-BTC were also compared with homogeneously dissolved $\mathrm{Cu}$ salts in order to classify the catalytic performance of the MOF catalyst. Therefore, $\mathrm{Cu}\left(\mathrm{NO}_{3}\right)_{2}$ and $\mathrm{Cu}(\mathrm{OAc})_{2}$ have been applied under identical reaction conditions, using the same amount of $\mathrm{Cu}$ that is present in the Cu-BTC catalyst. However, a selective hydroxylation of

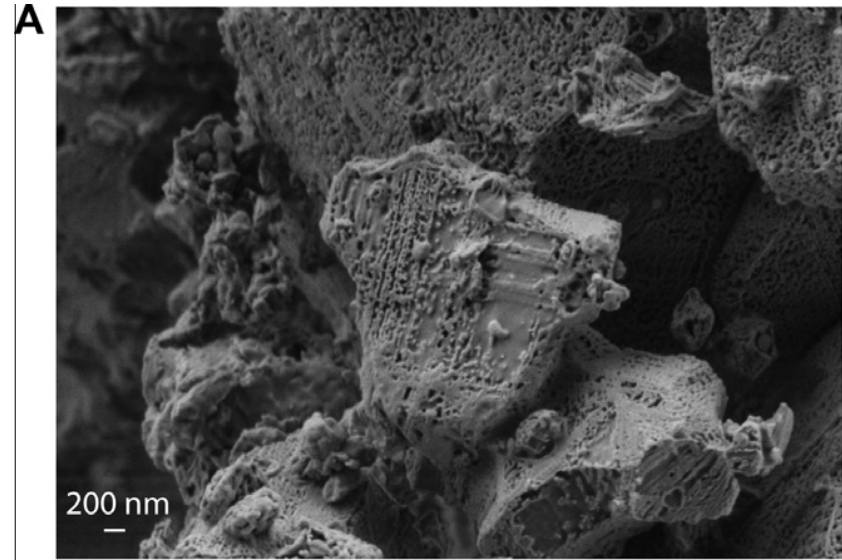

B

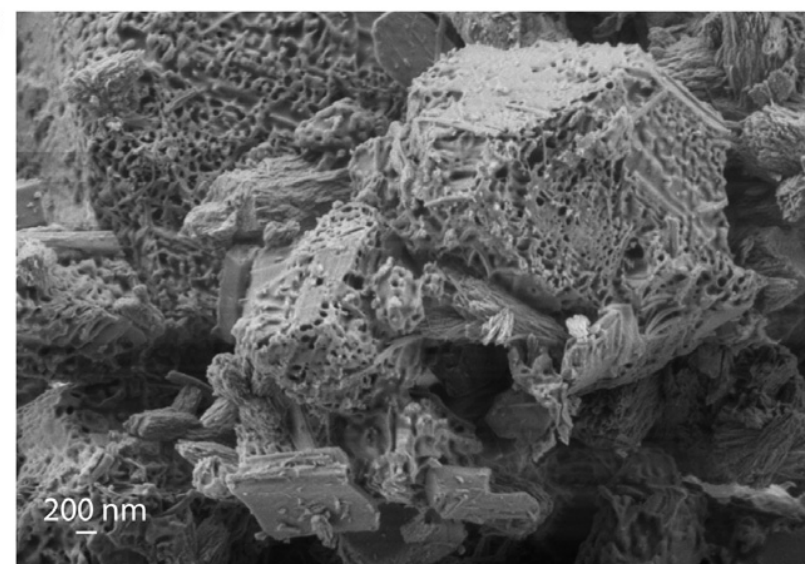

Fig. 9. Comparison of morphologies of $\mathrm{Cu}-\mathrm{BTC}(\mathrm{A})$ and $\mathrm{Cu}-\mathrm{BTC}_{0.5} \mathrm{PyDC}_{0.5}$ (B), as emerging from SEM investigations (white bar indicates $200 \mathrm{~nm}$ ).

toluene could not be observed under the chosen conditions. In the presence of the dissolved $\mathrm{Cu}$ salts, the reaction mixture changed its color to deep red even at low reaction temperatures (40 or $50^{\circ} \mathrm{C}$ ) and a huge variety of side products could be found in GC analysis. From these observations, we conclude that the heterogeneous MOF catalyst represents the catalytically active species facilitating a direct hydroxylation of toluene with high selectivity toward the cresols. However, a possible contribution of leached species cannot be ruled out completely. By means of AAS, 3\% of the total amount of copper was detected in the aqueous phase, though these dissolved $\mathrm{Cu}$ species will probably favor the undesired side reactions toward benzaldehyde or methylbenzoquinone. Despite the observed leaching, catalyst separation and copper contamination of the product do not represent a major problem, since soluble copper species were only found in the aqueous phase. The organic phase did not contain $\mathrm{Cu}$ in concentrations that could be detected within the limits of AAS.

The product selectivity for the oxidation of toluene in the presence of Cu-BTC using acetonitrile as the solvent is visualized in Fig. 10. Under these conditions, significant amounts of the side products methylquinone, benzaldehyde, and benzyl alcohol were observed in addition to the desired ortho- and para-cresol. Nevertheless, with increasing temperature (from $40^{\circ} \mathrm{C}$ to $80^{\circ} \mathrm{C}$ ), the formation of ortho- and para-cresol became favored again on the cost of benzaldehyde formation. In contrast to the solvent-free studies (vide infra), where the ratio of ortho- and para-cresol depended on temperature (with ortho-cresol being favored at higher temperatures), the ortho-cresol was favored over the whole temperature range. Obviously, the reaction temperature is strongly influencing the chemoselectivity, whereas the regioselectivity is only affected 


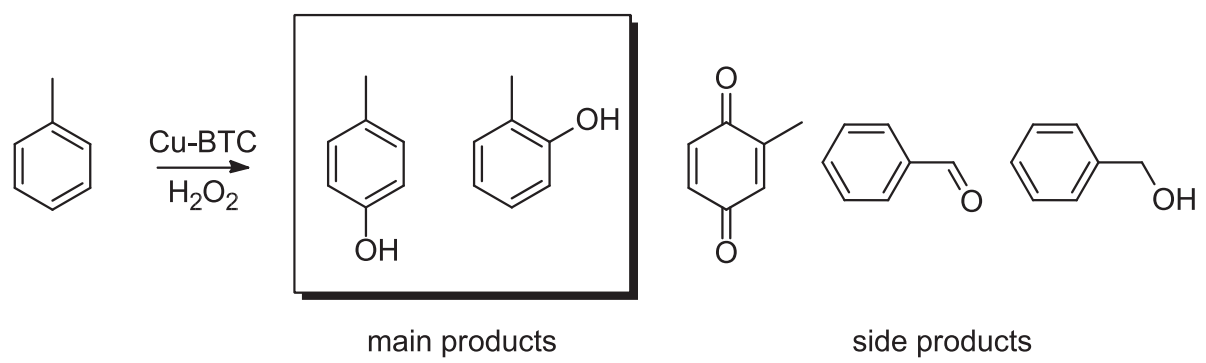

Scheme 2. Reaction scheme for the oxidation of toluene.

Table 2

Conversion of toluene in acetonitrile as solvent under different reaction conditions (catalyst: $\mathrm{Cu}-\mathrm{BTC}$, eq. $\mathrm{H}_{2} \mathrm{O}_{2}=2$ ).

\begin{tabular}{clcll}
\hline Entry & Temperature $\left({ }^{\circ} \mathrm{C}\right)$ & Time $(\mathrm{h})$ & Substrate $($ vol.\%) & Conversion $(\%)$ \\
\hline 1 & 40 & 1 & 10 & 0.14 \\
2 & 40 & 2 & 10 & 0.22 \\
3 & 40 & 3 & 10 & 0.39 \\
4 & 40 & 18 & 10 & 0.46 \\
5 & 50 & 1 & 10 & 0.21 \\
6 & 50 & 3 & 10 & 1.0 \\
7 & 50 & 18 & 10 & 1.66 \\
8 & 60 & 1 & 10 & 0.2 \\
9 & 60 & 2 & 10 & 0.46 \\
10 & 60 & 3 & 10 & 3.7 \\
11 & 70 & 1 & 10 & 0.9 \\
12 & 70 & 2 & 10 & 1.5 \\
13 & 80 & 1 & 10 & 1.27 \\
14 & 80 & 1 & 5 & 4.91
\end{tabular}

a The amount of hydrogen peroxide was kept constant; thus 4 equivalents were used.

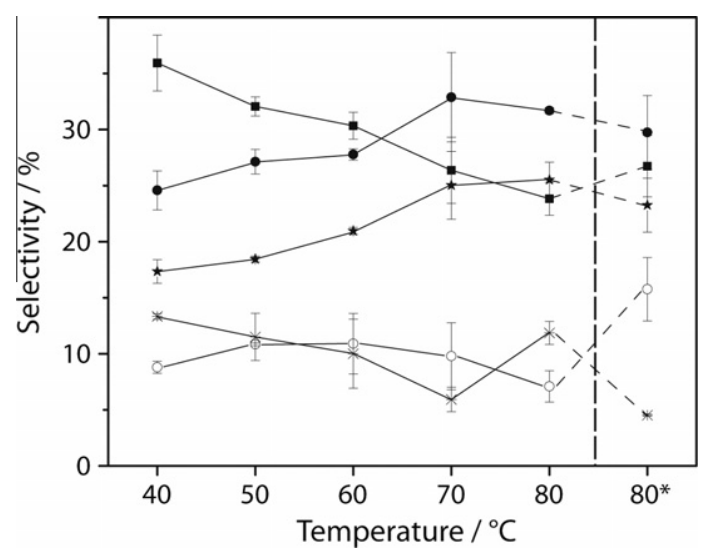

Fig. 10. Influence of the temperature on the selectivity. Substrate: toluene, catalyst: Cu-BTC, solvent: acetonitrile, vol.\% substrate $=10 \%$, time: $1 \mathrm{~h}, 2$ eq. $\mathrm{H}_{2} \mathrm{O}_{2}$. $(\mathbb{\square})=$ benzaldehyde, $(\bullet)=0$-cresol, $(\star)=$ p-cresol, $(*)=$ benzyl alcohol, $(O)=$ methylquinone. The values given on the right side of the diagram indicate the product distribution of a diluted sample $\left(T=80^{\circ} \mathrm{C}\right.$, vol. $\%$ substrate $=5 \%$, catalyst $=\mathrm{Cu}-\mathrm{BTC}$, time $=1 \mathrm{~h}, 4 \mathrm{eq} . \mathrm{H}_{2} \mathrm{O}_{2}$ ). The error bars give an indication of the reproducibility of the experiments.

to a minor extent. The aldehyde (side chain oxidation) was found as the main product at low temperatures, while at higher temperature the quinone (further oxidation of the ring) was favored. A further dilution of the substrate from 10 vol.\% to 5 vol.\% led to an increased conversion (1.27\% vs. 4.91\%, Table 2, entries 13 and 14 ) but had a negative influence on the selectivity (Fig. 10). While ortho- (32\%) and para-cresol (26\%) were favored over benzaldehyde $(24 \%)$ for the high substrate concentration, dilution of the substrate caused a decreased selectivity toward the cresols $(27 \%$ and $22 \%$, respectively), and benzaldehyde was found as the main

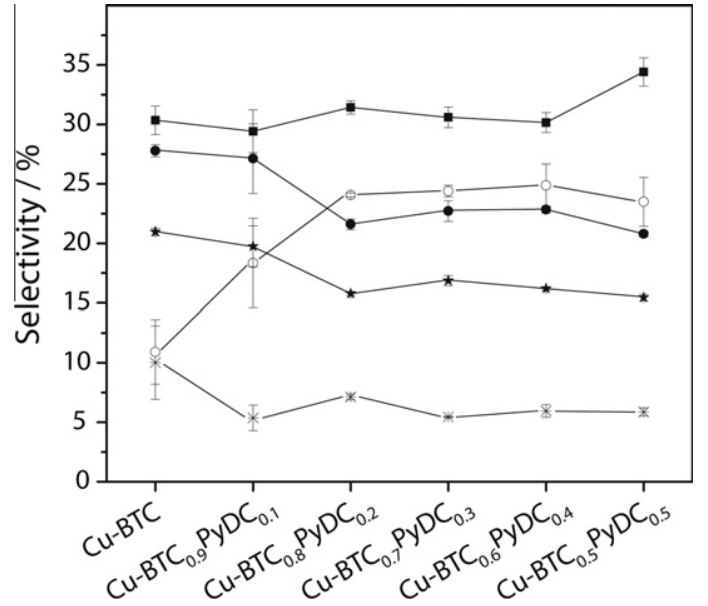

Fig. 11. Influence of the MOF composition on the product distribution. Substrate: toluene, solvent: acetonitrile, vol.\% substrate $=10 \%, T=60^{\circ} \mathrm{C}$, reaction time $=1 \mathrm{~h}$, 2 eq. $\mathrm{H}_{2} \mathrm{O}_{2}$. $(\boldsymbol{\square})=$ benzaldehyde, $(\bullet)=0$-cresol, $(\star)=$ p-cresol, $(*)=$ benzyl alcohol, $(\bigcirc)=$ methylquinone. The error bars give an indication of the reproducibility of the experiments.

product (29\%). Therefore, the following studies were performed under solvent-free conditions (in neat substrate) in order to obtain a high selectivity toward the desired cresols.

The substituted Cu-BTC-PyDC materials were also tested in the hydroxylation of toluene. Interestingly, the conversion for the substituted MOFs was much higher and reached more than $3 \%$ at $60{ }^{\circ} \mathrm{C}$ compared to $0.3 \%$ for the unmodified Cu-BTC (see Table 2, entry 8 for comparison).

In addition to the substrate conversion, also the product selectivity was significantly influenced by the introduction of PyDC to the framework (Fig. 11). Pyridine did not only influence the electronic properties of the copper ions, but might also have changed some other properties of the material, e.g., its basicity by the presence of the pyridine moiety. Thus, the observed selectivity for the pure $\mathrm{Cu}-\mathrm{BTC}$ was significantly different from that found in case of the modified Cu-BTC-PyDCs. Noticeably, the degree of substitution did not have a major effect, as more or less the same product distribution was achieved for all MIXMOFs. For all Cu-BTC-PyDC materials, a distinct increase in the methylbenzoquinone selectivity was observed, while the concentration of the two cresols dropped (from $28 \%$ and $22 \%$, respectively, for Cu-BTC to ca. $22 \%$ and $15 \%$ for the materials substituted with $20 \%$ or more of PyDC). Apparently, under these conditions, further oxidation of the aromatic ring was favored over its hydroxylation. Independent of these trends, benzaldehyde (30-38\%) was the main product with all catalysts.

In addition to the parameter studies, recycling experiments have been performed with $\mathrm{Cu}-\mathrm{BTC}$ and $\mathrm{Cu}-\mathrm{BTC}_{0.6} \mathrm{PyDC}_{0.4}$ at $60^{\circ} \mathrm{C}$. For pure $\mathrm{Cu}-\mathrm{BTC}$, an improvement of the conversion from $0.2 \%$ 
$( \pm 0.1)$ for the first run up to $1.42 \%( \pm 0.002)$ was observed. Only slight changes in the selectivity have been observed for the recycle experiments (SI, Fig. S4). The powder XRD pattern of the used $\mathrm{Cu}-$ BTC material (SI, Fig. S5) indicated no structural change in the material after four experiments.

$\mathrm{Cu}-\mathrm{BTC}_{0.6} \mathrm{PyDC}_{0.4}$ did not exhibit a significant change in conversion after 3 runs (average conversion of three runs $=2.7 \%$, standard deviation of the three runs $=0.3 \%$ ) or selectivity upon reuse (SI, Fig. S6).

\subsubsection{Solvent-free oxidation of aromatic substrates}

3.2.2.1. Influence of reaction temperature and oxidant concentration. Based on the previous findings, $\mathrm{Cu}$-BTC was tested in the solvent-free oxidation reaction of aromatic compounds (e.g., neat toluene) using hydrogen peroxide as the oxidant. Note that the overall conversion of toluene and the other substrates under these conditions was $<1 \%$, caused by the huge excess of the substrate. As already indicated by the dilution experiments (see Section 3.2.1), the catalyst did not significantly promote the oxidation of the side chain to obtain benzyl alcohol, benzaldehyde, or benzoic acid, but a direct hydroxylation of the aromatic ring could be observed with a strong selectivity toward the para- and ortho-substituted products in the absence of a solvent. In the reaction of toluene at $80^{\circ} \mathrm{C}$, only small quantities of benzaldehyde and methylquinone were found in addition to the main products ortho- and para-cresol. The chemo- and regioselectivity of the test reaction were investigated under several reaction conditions.

In Fig. 12, the selectivity toward ortho-, para-cresol, benzaldehyde and methylbenzoquinone at $80^{\circ} \mathrm{C}$ is depicted for different amounts of hydrogen peroxide and after different reaction times. After one hour of reaction time, ortho-cresol (41\% selectivity) was the main product, followed by para-cresol (38\%), methylbenzoquinone $(11 \%)$, and benzaldehyde (10\%) using the lowest oxidant concentration. Increasing the $\mathrm{H}_{2} \mathrm{O}_{2}$ quantity led to an increased production of the over-oxidized product methylbenzoquinone (21\%), while the selectivity of the two cresols decreased (37\% and $28 \%$ ). The same trend was observed after reaction times of two and three hours, respectively. (SI Fig. S7 top and bottom). Therefore, 0.2 equivalents of $\mathrm{H}_{2} \mathrm{O}_{2}$ (with respect to the substrate) were used in the further tests.

Besides the oxidant concentration, also temperature affected the product distribution significantly. In contrast to the former, over-oxidation to quinone was not a major problem here (e.g., $4 \%$ at $40{ }^{\circ} \mathrm{C}$ and $11 \%$ at $80^{\circ} \mathrm{C}$ ). However, the regioselectivity of the cresols could be influenced significantly by variation in the reaction

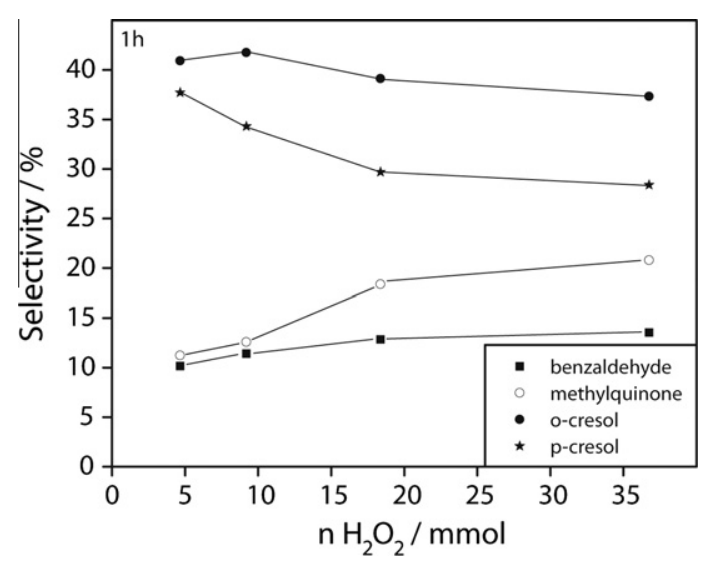

Fig. 12. Influence of the oxidant concentration on the product selectivity after one hour reaction time. Substrate: toluene, catalyst: Cu-BTC, no solvent, $T=80^{\circ} \mathrm{C}$, vol.\% substrate $=10 \%$. temperature. At low temperatures of 40 or $50{ }^{\circ} \mathrm{C}$, the highest selectivity after one hour was obtained for para-cresol (47\%, compared to $34 \%$ of the ortho-product; Fig. 13). With increasing temperature (starting at $50-60{ }^{\circ} \mathrm{C}$ ), a decreased selectivity to para-cresol was observed, and the ortho-product became the dominant one. At a reaction temperature of $80{ }^{\circ} \mathrm{C}$, para- and ortho-cresol were formed with a selectivity of $34 \%$ and $41 \%$, respectively. No conversion was observed in the absence of the catalyst (SI, Fig. S8 top and bottom).

3.2.2.2. Variation of Substrates. In addition to toluene, a variety of other aromatic substrates were used in the test reaction to check scope and limitations. The non-substituted benzene should yield only phenol as the main product and benzoquinone as side product. Compared to toluene, higher conversions could be obtained for benzene (vide infra). In accordance with the toluene reaction, the total conversion increased at higher temperatures (SI, Fig. S9 top), while the selectivity toward phenol decreased. A similar trend was found with increased $\mathrm{H}_{2} \mathrm{O}_{2}$ amount (SI, Fig. S9 bottom). However, using an optimized reaction temperature of $40^{\circ} \mathrm{C}$ phenol could be detected as the only product of the reaction after one hour. No benzene conversion was observed in the absence of the catalyst.

In accordance with the findings made for toluene, also xylenes could be converted in the test reaction, albeit at very little conversion. 2,5-dimethylphenol was the only product observed in the reaction of para-xylene, whereas the reaction of ortho-xylene gave surprising results concerning the regioselectivity. While exclusively 2,3-dimethylphenol was obtained at $40^{\circ} \mathrm{C}$, the selectivity toward this isomer $(41 \%)$ was reduced significantly at a reaction temperature of $50{ }^{\circ} \mathrm{C}$, and the other regioisomer 3,4-dimethylphenol (59\%) became the main product. The decrease of conversion in the order benzene $>$ toluene $>p$-xylene $>0$-xylene indicates that the size and steric hindrance of the reactants may play a role and suggests that diffusion processes might be a limiting factor for the efficiency of this catalytic reaction (Table 3 ).

In addition to toluene and benzene, also other substrates have been screened in the reaction to investigate possible electronic and steric influences. The results are listed in Table 3. A comparison of the three aryl halides (fluoro-, chloro-, and bromobenzene) showed that also for these substrates, the para-isomer was obtained with highest selectivity at $40{ }^{\circ} \mathrm{C}(53-61 \%$, see Table 3$)$. In contrast to the observations made for toluene, increasing the temperature to $50{ }^{\circ} \mathrm{C}$ did not significantly change the selectivity for chloro- and bromobenzene. Interestingly, higher reaction temperature resulted in higher para-selectivity $\left(69 \%\right.$ at $50{ }^{\circ} \mathrm{C}$ compared

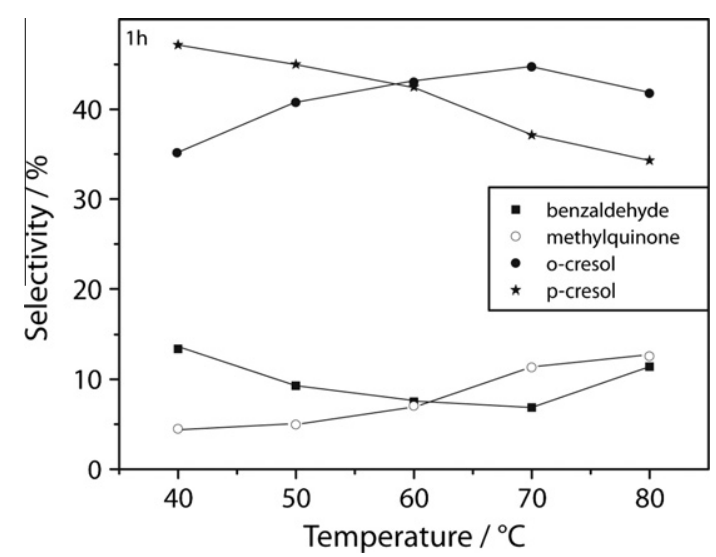

Fig. 13. Influence of the reaction temperature on the product selectivity after one hour reaction time. Substrate: toluene, conditions: 0.2 equivalents of $\mathrm{H}_{2} \mathrm{O}_{2}$, catalyst $=\mathrm{Cu}-\mathrm{BTC}$. 
Table 3

Solvent-free oxidation of various aromatic substrates. (Catalyst: $\mathrm{Cu}-\mathrm{BTC}$, reaction time $=1 \mathrm{~h}$; eq. $\mathrm{H}_{2} \mathrm{O}_{2}=0.2$ ).

\begin{tabular}{|c|c|c|c|c|c|}
\hline Entry & Substrate & $T\left({ }^{\circ} \mathrm{C}\right)$ & Conversion (\%) & Products & Selectivity (\%) \\
\hline 1 & Toluene & 40 & 0.04 & $\begin{array}{l}\text { Benzaldehyde } \\
\text { Methylbenzoquinone } \\
o \text {-Cresol } \\
\text { p-Cresol }\end{array}$ & $\begin{array}{l}12 \\
4 \\
36 \\
47\end{array}$ \\
\hline 2 & & 50 & 0.07 & $\begin{array}{l}\text { Benzaldehyde } \\
\text { Methylbenzoquinone } \\
o \text {-Cresol } \\
\text { p-Cresol }\end{array}$ & $\begin{array}{l}10 \\
5 \\
39 \\
46\end{array}$ \\
\hline 3 & Benzene & 40 & 0.04 & $\begin{array}{l}\text { Phenol } \\
\text { Benzoquinone }\end{array}$ & $\begin{array}{l}>99.9 \\
<0.1\end{array}$ \\
\hline 4 & & 50 & 0.11 & $\begin{array}{l}\text { Phenol } \\
\text { Benzoquinone }\end{array}$ & $\begin{array}{l}90 \\
10\end{array}$ \\
\hline 5 & Para-xylene & $\begin{array}{l}40 \\
50\end{array}$ & $\begin{array}{l}0.003 \\
0.006\end{array}$ & $\begin{array}{l}\text { 2,5-Dimethylphenol } \\
\text { 2,5-Dimethylphenol }\end{array}$ & $\begin{array}{l}>99.9 \\
>99.9\end{array}$ \\
\hline 6 & Ortho-xylene & 40 & 0.001 & $\begin{array}{l}\text { 2,3-Dimethylphenol } \\
\text { 3,4-Dimethylphenol }\end{array}$ & $\begin{array}{l}>0.1 \\
<99.9\end{array}$ \\
\hline 7 & & 50 & 0.004 & $\begin{array}{l}\text { 2,3-Dimethylphenol } \\
\text { 3,4-Dimethylphenol }\end{array}$ & $\begin{array}{l}41 \\
59\end{array}$ \\
\hline 8 & Fluorobenzene & 40 & 0.003 & $\begin{array}{l}\text { Para-fluorophenol } \\
\text { Ortho-fluorophenol }\end{array}$ & $\begin{array}{l}61 \\
39\end{array}$ \\
\hline 9 & & & 0.009 & $\begin{array}{l}\text { Para-fluorophenol } \\
\text { Ortho-fluorophenol }\end{array}$ & $\begin{array}{l}69 \\
31\end{array}$ \\
\hline 10 & Chlorobenzene & & 0.016 & $\begin{array}{l}\text { Para-chlorophenol } \\
\text { Ortho-chlorophenol }\end{array}$ & $\begin{array}{l}53 \\
47\end{array}$ \\
\hline 11 & & 50 & 0.06 & $\begin{array}{l}\text { Para-chlorophenol } \\
\text { Ortho-chlorophenol }\end{array}$ & $\begin{array}{l}53 \\
47\end{array}$ \\
\hline 12 & Bromobenzene & 40 & 0.014 & $\begin{array}{l}\text { Para-bromophenol } \\
\text { Ortho-bromophenol }\end{array}$ & $\begin{array}{l}57 \\
43\end{array}$ \\
\hline 13 & & 50 & 0.03 & $\begin{array}{l}\text { Para-bromophenol } \\
\text { Ortho-bromophenol }\end{array}$ & $\begin{array}{l}56 \\
44\end{array}$ \\
\hline
\end{tabular}

to $61 \%$ at $40^{\circ} \mathrm{C}$ ) for fluorobenzene. No quinone species could be detected for all three aryl halides under the reaction conditions used. Since the conversion of the halogenated aromatic compounds was much smaller compared to toluene, with fluorobenzene having the smallest conversion, it is assumed that the electron-withdrawing properties of the halide substituents deactivate the aromatic compound for that reaction.

3.2.2.3. Mechanistic considerations. In order to gain some insight whether the reaction proceeds via a radical mechanism or not,

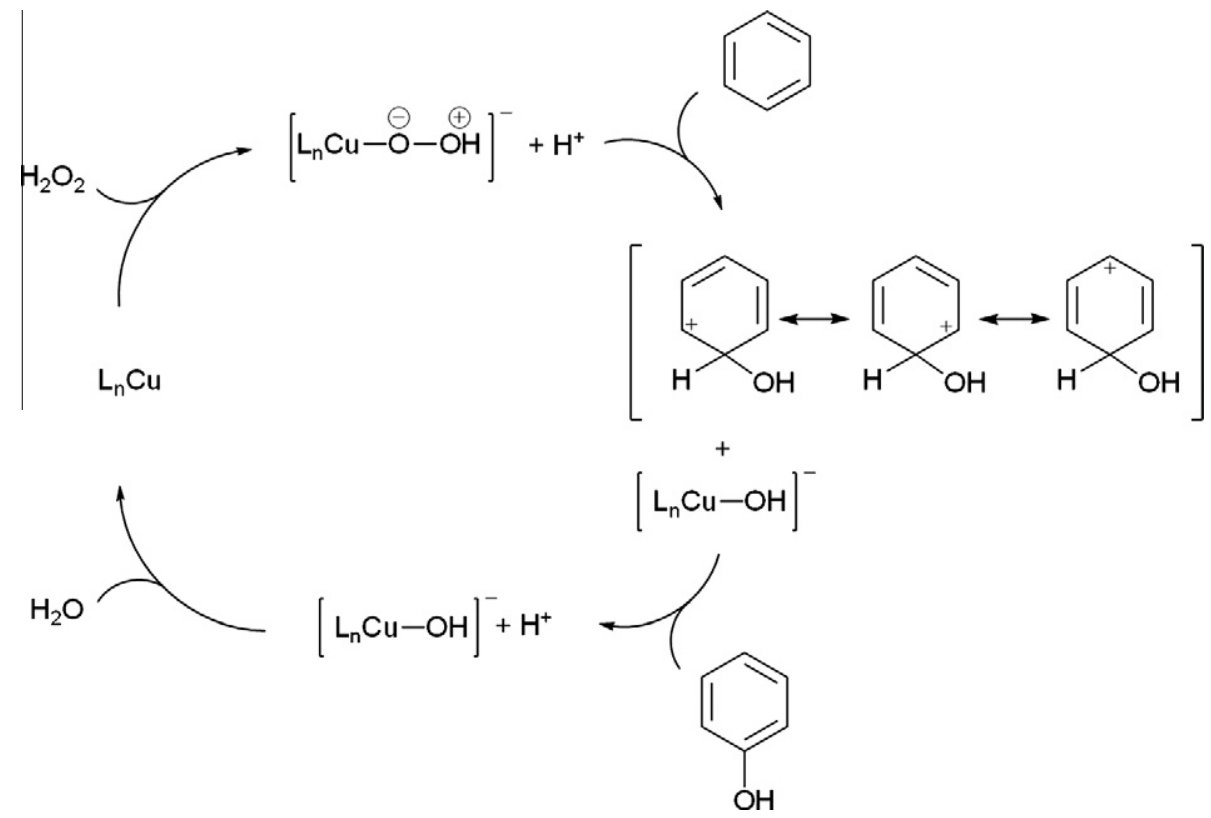

Scheme 3. Feasible mechanism for the hydroxylation of aromatic compounds (exemplarily shown for benzene). 
hydrochinone was added to the reaction mixture as a scavenger. Under solvent-less conditions, the presence of hydrochinone did not stop the hydroxylation of toluene, indicating a non-radical reaction mechanism.

This assumption is supported by the absence of meta-cresol, which could be a possible product in a radical reaction, and the low selectivity toward oxidation of the methyl group of toluene that should be favored due to stabilization of the radical in benzylic position. Further evidence of an ionic mechanism is given by the fact that the conversion of fluorobenzene is much smaller compared to that of chlorobenzene or bromobenzene. Fluorine is known to be a substituent that deactivates aromatic compounds for the electrophilic, aromatic substitution. Taking the aforementioned arguments into account, we favor an ionic pathway similar to an electrophilic, aromatic substitution. Hydrogen peroxide is activated by the copper ions, and a species like $\mathrm{OH}^{+}$is transferred to the aromatic system $[45,46]$. After release of a proton, the hydroxylated aromatic product is generated, while water is released as by-product (Scheme 3) Nevertheless, an activation of a hydrogen peroxide molecule at a $\mathrm{Cu}$ dimer can be virtually excluded, since the water molecules are axially located at the two copper centers (Fig. 1, bottom) and thus antipodal ( $180^{\circ}$ angle) and pointing toward different pores. Therefore, the calculation of TOFs is done with the assumption that a single $\mathrm{Cu}$ ion activates one hydrogen peroxide molecule.

\section{Conclusions}

We have synthesized new MIXMOF materials based on the structure of the metal-organic framework Cu-BTC. Up to $50 \%$ of the benzene-1,3,5-tricarboxylate (BTC) linkers could be replaced by pyridine-3,5-dicarboxylate (PyDC) without changing the crystal structure of the resulting materials, as confirmed by X-ray powder diffraction. X-ray absorption spectroscopy (XAS) revealed that the incorporation of the pyridine moiety into the crystal lattice leads to a local defect site at some of the dimeric $\mathrm{Cu}$ units, where normally a bridging carboxylate group would be coordinated. These structural defects cause a modified chemical and electronic environment of the metal centers, which consequently also affects their accessibility and activity in catalytic applications.

Cu-BTC and the substituted Cu-BTC-PyDC materials were found to catalyze the direct hydroxylation of aromatic compounds at low temperatures. In contrast to homogeneously dissolved $\mathrm{Cu}$ salts, a surprisingly high selectivity toward ortho- and para-cresol was observed in the reaction of toluene and hydrogen peroxide. As expected, the product selectivity was significantly different for pure $\mathrm{Cu}-\mathrm{BTC}$ and the mixed-linker materials. Using acetonitrile as the solvent, a maximum turnover frequency of up to $2.37 \mathrm{~h}^{-1}$ could be reached which is twice as high as TOFs that have been reported in literature before. The toluene concentration had a dramatic and opposed influence on the conversion and the product selectivity. Lower substrate concentrations led to an increased conversion, but also to an increased selectivity toward the undesired side products benzaldehyde and methylbenzoquinone. Consequently, high selectivity toward the cresol products was observed under solvent-free conditions. Using optimized reaction conditions, the direct hydroxylation of other aromatic substrates including benzene, xylenes, and aryl halides became feasible.

\section{Acknowledgments}

The authors thank Hasylab at DESY for providing beamtime at beamline X1 and Prof. Jan-Dierk Grunwaldt (KIT) for valuable discussions as well as the European Union for financial support (contract number I-2009 0282 EC). Dr. Frank Krumeich and the EMEZ
(Electron Microscopy ETH Zurich) are acknowledged for microscope time and recording of SEM pictures and Dr. Marek Maciejewski (ETH Zurich) for performing the TG analysis.

\section{Appendix A. Supplementary material}

Supplementary data associated with this article can be found, in the online version, at doi:10.1016/j.jcat.2011.04.004.

\section{References}

[1] U. Mueller, M. Schubert, F. Teich, H. Puetter, K. Schierle-Arndt, J. Pastré, J. Mater. Chem. 16 (2006) 626-636.

[2] J.Y. Lee, O.K. Farha, J. Roberts, K.A. Scheidt, S.B.T. Nguyen, J.T. Hupp, Chem. Soc. Rev. 38 (2009) 1450-1459.

[3] M. Sabo, A. Henschel, H. Fröde, E. Klemm, S. Kaskel, J. Mater. Chem. 17 (2007) 3827-3832.

[4] S. Hermes, M.K. Schröter, R. Schmid, L. Khodeir, M. Muhler, A. Tissler, R.W. Fischer, R.A. Fischer, Angew. Chem. Int. Ed. 44 (2005) 6237-6241.

[5] S. Hermes, F. Schröder, S. Amirjalayer, R. Schmid, R.A. Fischer, J. Mater. Chem 16 (2006) 2464-2472.

[6] S. Opelt, S. Türk, E. Dietzsch, A. Henschel, S. Kaskel, E. Klemm, Catal. Commun. 9 (2008) 1286-1290

[7] F. Schröder, S. Henke, X. Zhang, R.A. Fischer, Eur. J. Inorg. Chem. (2009) 31313140.

[8] W. Kleist, M. Maciejewski, A. Baiker, Thermochim. Acta 499 (2010) 71-78.

[9] J. Gascon, U. Aktay, M.D. Hernandez-Alonso, G.P.M. van Klink, F. Kapteijn, J. Catal. 261 (2009) 75-87.

[10] W. Kleist, F. Jutz, M. Maciejewski, A. Baiker, Eur. J. Inorg. Chem. (2009) $3552-$ 3561 .

[11] A.D. Burrows, C.G. Frost, M.F. Mahon, C. Richardson, Angew. Chem. Int. Ed. 47 (2008) 8482-8486.

[12] Z. Wang, S.M. Cohen, Angew. Chem. Int. Ed. 47 (2008) 4699-4702.

[13] Z. Wang, S.M. Cohen, J. Am. Chem. Soc. 131 (2009) 16675-16677.

[14] X. Zhang, F.X. Llabrés i Xamena, A. Corma, J. Catal. 265 (2009) 155-160.

[15] C.D. Wu, A. Hu, L. Zhang, W. Lin, J. Am. Chem. Soc. 127 (2005) 8940-8941.

[16] C.D. Wu, W. Lin, Angew. Chem. Int. Ed. 46 (2007) 1075-1078.

[17] C.D. Wu, L. Zhang, W. Lin, Inorg. Chem. 45 (2006) 7278-7285.

[18] L. Alaerts, E. Séguin, H. Poelman, F. Thibault-Starzyk, P.A. Jacobs, D.E. De Vos, Chem. Eur. J. 12 (2006) 7353-7363.

[19] F.X. Llabrés i Xamena, A. Abad, A. Corma, H. Garcia, J. Catal. 250 (2007) 294298.

[20] A. Dhakshinamoorthy, M. Alvaro, H. Garcia, J. Catal. 267 (2009) 1-4.

[21] S.S.Y. Chui, S.M.F. Lo, J.P.H. Charmant, A.G. Orpen, I.D. Williams, Science 283 (1999) 1148-1150.

[22] D.J. Tranchemontagne, J.R. Hunt, O.M. Yaghi, Tetrahedron 64 (2008) 85538557.

[23] A. Vishnyakov, P.I. Ravikovitch, A.V. Neimark, M. Bülow, Q.M. Wang, Nano Lett 3 (2003) 713-718.

[24] E. Biemmi, S. Christian, N. Stock, T. Bein, Micropor. Mesopor. Mater. 117 (2009) 111-117.

[25] Z.Q. Li, L.G. Qiu, T. Xu, Y. Wu, W. Wang, Z.Y. Wu, X. Jiang, Mater. Lett. 63 (2009) 78-80.

[26] Y.K. Seo, G. Hundal, I.T. Jang, Y.K. Hwang, C.H. Jun, J.S. Chang, Micropor Mesopor. Mater. 119 (2009) 331-337.

[27] C. Shekhah, H. Wang, S. Kowarik, F. Schreiber, M. Paulus, M. Tolan, C. Sternemann, F. Evers, D. Zacher, R.A. Fischer, C. Wöll, J. Am. Chem. Soc. 129 (2007) 15118-15119.

[28] J. Gascon, S. Aguado, F. Kapteijn, Micropor. Mesopor. Mater. 113 (2008) 132138.

[29] D. Zacher, O. Shekhah, C. Wöll, R.A. Fischer, Chem. Soc. Rev. 38 (2009) 1418 1429.

[30] J.G. Vitillo, L. Regli, S. Chavan, G. Ricchiardi, G. Spoto, P.D.C. Dietzel, S. Bordiga A. Zecchina, J. Am. Chem. Soc. 130 (2008) 8386-8396.

[31] A. Martin-Calvo, E. Garcia-Pérez, J.M. Castillo, S. Calero, Phys. Chem. Chem. Phys. 10 (2008) 7085-7091.

[32] T. Düren, Y.-S. Bae, R.Q. Snurr, Chem. Soc. Rev. 38 (2009) 1237-1247.

[33] R. Babarao, J. Jiang, S.I. Sandler, Langmuir 25 (2009) 5239-5247.

[34] K. Schlichte, T. Kratzke, S. Kaskel, Micropor. Mesopor. Mater. 73 (2004) 81-88

[35] Y. Wu, L.-G. Qiu, W. Wang, Z.-Q. Li, T. Xu, Z.-Y. Wu, X. Jiang, Trans. Metal Chem. 34 (2009) 263-268.

[36] K. Brown, S. Zolezzi, P. Aguirre, D. Venegas-Yazigi, V. Paredes-Garcia, R. Baggio, M.A. Novak, E. Spodine, Dalton Trans. (2009) 1422-1427.

[37] R. Raja, P. Ratnasamy, Appl. Catal. A: Gen. 143 (1996) 145-158.

[38] B. Lücke, K.V. Narayana, A. Martin, K. Jähnisch, Adv. Synth. Catal. 346 (2004) 1407-1424.

[39] J.J. Rehr, C.H. Booth, F. Bridges, S.I. Zabinsky, Phys. Rev. B 49 (1994) $12347-$ 12350.

[40] C. Prestipino, L. Regli, J.G. Vitillo, F. Bonino, A. Damin, C. Lamberti, A. Zecchina, P.L. Solari, K.O. Kongshaug, S. Bordiga, Chem. Mater. 18 (2006) 1337-1346.

[41] J. Stötzel, D. Lützenkirchen-Hecht, R. Frahm, B. Kimmerle, A. Baiker, M. Nachtegaal, M.J. Beier, J.D. Grunwaldt, 14th International Conference on X-Ray Absorption Fine Structure (Xafs14), Proceedings, vol. 190, 2009. 
[42] N. Drenchev, E. Ivanova, M. Mihaylov, K. Hadjiivanov, Phys. Chem. Chem. Phys 12 (2010) 6423-6427.

[43] K.L. Gurunatha, T.K. Maji, Eur. J. Inorg. Chem. 12 (2009) 1592-1599.

[44] D. Zhao, N. Wu, S. Zhang, P. Xi, X. Su, J. Lan, J. You, Angew. Chem. Int. Ed. 48 (2009) 8729-8732.
[45] C.N. Kato, M. Hasegawa, T. Sato, A. Yoshizawa, T. Inoue, W. Mori, J. Catal. 230 (2005) 226-236.

[46] A.V. Ramaswamy, S. Sivasanker, P. Ratnasamy, Micropor. Mater. 2 (1994) 451458. 